\title{
O Efeito da Volatilidade da Taxa de Câmbio sobre o Comércio Internacional: Uma Investigação Empírica sob a Ótica da Margem Extensiva
}

\author{
Alex Sander Souza do Carmo \\ Professor - Universidade Estadual de Ponta Grossa (UEPG) \\ Endereço: Campus Central - Praça Santos Andrade, $n^{\circ}$ - 1 - Ponta Grossa /PR - Brasil \\ CEP: 84010-919 - E-mail: acarmo@uepg.br
}

\section{Maurício Vaz Lobo Bittencourt}

Professor - Universidade Federal do Paraná (PPGDE-UFPR)

Endereço: Av. Prefeito Lothário Meissner, 632 - térreo, Jardim Botânico - Curitiba /PR - Brasil

CEP: 80210-170 - E-mail: mbittencourt@ufpr.br

Recebido em 21 de outubro 2012. Aceito em 09 de maio de 2014.

\section{Resumo}

O objetivo do presente trabalho é analisar o efeito da volatilidade da taxa de câmbio sobre a margem extensiva do comércio internacional. Em termos metodológicos, definiu-se como margem extensiva do comércio internacional o número de produtos exportados pelos países para os seus parceiros comerciais. Posteriormente, essa variável foi inserida como dependente em um modelo gravitacional de comércio, cujos parâmetros foram estimados pela técnica de dados em painel não linear. O período de análise compreendido no presente trabalho foi de 1995 a 2009, e o número de países considerados no estudo foi 54 . Os principais resultados indicaram que uma elevação na volatilidade da taxa de câmbio causa uma redução na margem extensiva do comércio internacional, reduzindo a diversificação da pauta de exportação dos países.

\section{Palavras-Chave}

Margem Extensiva, Firmas Heterogêneas, Equação Gravitacional, Máxima VerossimiIhança de Poisson

\begin{abstract}
The main purpose of this paper is to analyze the effect of exchange rate volatility on the extensive margin of international trade. In methodological terms, we defined as the extensive margin of international trade, the number of products exported by countries to their trading partners. Later, this variable was specified as dependent variable on a gravity model of trade, whose parameters were estimated by nonlinear panel data. The period of analysis in this work was from 1995 to 2009 and the number of countries considered in the study was 54 . The results indicate that an increase in the volatility of the exchange rate causes a reduction on the extensive margin of international trade.
\end{abstract}

\section{Keywords}

Extensive Margin, Heterogeneous Firms, Gravity Equation, Poisson Maximum likelihood

\author{
JEL Classification \\ F10, F15
}




\section{Introdução}

Após o colapso do sistema de Bretton Woods, ${ }^{1}$ no início dos anos setenta, as taxas de câmbio dos países deixaram de ser fixas para se tornarem flutuantes. Diante desse novo contexto, tanto trabalhos teóricos quanto empíricos passaram a investigar os efeitos da volatilidade da taxa de câmbio sobre os fluxos comerciais.

Após quatro décadas de investigações, as evidências encontradas na literatura estão longe de serem conclusivas, pois os resultados obtidos afirmam que os efeitos da volatilidade da taxa de câmbio sobre os fluxos comerciais podem ser negativos (Dell' Ariccia, 1999, Rose, 2000; Clark et al., 2004; Bittencourt et al., 2007) positivos (Mackenzie; Brooks, 1997; Mackenzie, 1998; Hwang; Lee, 2005), ou ainda inexistentes (Kumar; Dhawan, 1991; Gagnon, 1993; Aristotelous, 2001). Ozturk (2006) destaca que a ambiguidade nos resultados obtidos está muito associada à escolha do período de tempo analisado, à especificação do modelo empírico, à proxy para a volatilidade cambial e também em relação aos países considerados no estudo, isto é, se os mesmos são desenvolvidos ou em desenvolvimento.

Um ponto em comum nesta literatura é que a análise da volatilidade da taxa de câmbio sobre os fluxos comerciais considera apenas a margem intensiva do comércio internacional, ou seja, esses trabalhos analisam apenas o efeito da volatilidade da taxa de câmbio sobre o volume monetário comercializado entre os países, negligenciando a outra parte do fluxo comercial, que corresponde à margem extensiva do comércio, onde se entende por margem extensiva o número de produtos comercializados.

Conforme Álvarez et al. (2009), analisar o efeito da volatilidade cambial sobre o comércio internacional é extremamente importante, pois se a volatilidade da taxa de câmbio realmente reduz o comércio, então os policy makers devem implementar políticas destinadas a reduzir esse tipo de volatilidade. Mas, outra questão igualmente importante, é compreender a forma com que a volatilidade cambial afeta os fluxos comerciais, ou seja, se o efeito ocorre por meio da margem intensiva, extensiva ou por ambas as margens. Nesse caso, se o efeito negativo não for somente sobre o volume, mas também

${ }_{1}$ Para maiores detalhes do Sistema de Bretton Woods, ver Williamson (1988, p. 322-328).

Estud. Econ., São Paulo, vol.44, n.4, p.815-845, out.-dez. 2014 
sobre o número total de produtos comercializados, as flutuações cambiais podem tornar os países mais dependentes de um conjunto mais reduzido de produtos de exportação. Dessa forma, Álvarez et al. (Ibidem) concluem que uma maior volatilidade cambial pode reduzir a capacidade dos países em expandir suas cestas de exportação, aumentando a sua vulnerabilidade aos choques externos.

Vale aqui frisar que a separação dos fluxos comerciais nas margens intensiva e extensiva surgiu na literatura a partir do desenvolvimento dos modelos teóricos de firmas heterogêneas, onde se destaca o trabalho seminal de Melitz (2003). Melitz estendeu o modelo de competição monopolística de Krugman (1980) por meio da inclusão da suposição de que as firmas são heterogêneas no que tange à produtividade. Como consequência, é possível endogeneizar o número de firmas exportadoras, e decompor os fluxos de comércio em termos de margem intensiva (volume monetário) e margem extensiva (número de produtos exportados).

A partir do modelo de Melitz (2003), uma série de modelos com firmas heterogêneas emergiu na literatura, entre os quais se pode destacar: Melitz e Ottaviano (2005), Falvey et al. (2004), Helpman et al. (2004), Yeaple (2005), Chaney (2008), Helpman et al. (2008) e Lin (2012). Lin (2012) desenvolve um modelo teórico com firmas heterogêneas que permite identificar os efeitos da volatilidade da taxa de câmbio sobre as margens intensiva e extensiva do comércio internacional, o qual será utilizado como referencial teórico do presente artigo. Ressalta-se que do ponto de vista empírico, os trabalhos que analisam os efeitos da volatilidade da taxa de câmbio sobre a margem extensiva de comércio ainda são relativamente escassos. Nesse campo de pesquisa encontram-se os estudos de Álvarez et al. (2009), Bergin e Lin (2009) e Lin (2012).

Diante de tal contexto, o objetivo central deste artigo é analisar o efeito da volatilidade da taxa de câmbio sobre a margem extensiva do comércio internacional. Destaca-se que o presente trabalho possui, pelo menos, duas características que o distingue dos estudos precedentes. A primeira é a utilização do número de produtos exportados pelos países como proxy da margem extensiva do comércio, em contraste com a metodologia desenvolvida por Hummels e Klenow (2005) usualmente utilizada. A segunda se refere à estratégia de estimação dos parâmetros, pois enquanto os estudos anteriores 
estimam o modelo empírico por meio de técnicas econométricas por Mínimos Quadrados Ordinários (MQO), este artigo estimará o modelo empírico por meio de técnicas de Poisson Pseudo Maximum Likelihood (PPML), conforme Santos Silva e Tenreyro (2005), pois a técnica PPML é mais robusta na presença de heterocedasticidade e não exclui das estimações os fluxos de comércio nulos.

Além desta introdução, o presente trabalho possui outras quatro seções. Na seção 2, discute-se o modelo teórico de firmas heterogêneas de Lin (2012). Na seção 3, descrevem-se o modelo empírico e a estratégia de estimação dos parâmetros. $\mathrm{Na}$ seção 4 , analisam-se os resultados. Por fim, na seção 5 , tem-se as considerações finais.

\section{Referencial Teórico}

$\mathrm{Na}$ introdução do presente trabalho se ressaltou que o objetivo central consiste em avaliar os efeitos da volatilidade da taxa de câmbio sobre a margem extensiva do comércio internacional, onde essa relação será analisada sob a ótica do modelo de firmas heterogêneas. Para tanto, descreve-se brevemente na presente seção o modelo teórico de firmas heterogêneas de Lin (2012), o qual será utilizado como suporte na análise empírica.

O modelo considera dois países (simétricos), que comercializam entre si. Em ambos os países, as firmas possuem níveis heterogêneos de produtividade, e a estrutura de mercado é de competição monopolística. Ademais, as firmas que desejam exportar os seus produtos necessitam pagar um custo fixo de entrada no mercado do parceiro comercial.

Assim, apenas as firmas mais produtivas, que conseguem gerar lucros positivos no mercado internacional, estão aptas a exportar. Em cada país, o consumidor consome todas as variedades no intervalo $[0,1)$, produzidas pelas firmas domésticas, e importam os bens no intervalo $\left[1+n^{*}, 2\right]$ produzidos pelas firmas estrangeiras. ${ }^{2}$ Cada consumi-

2 O autor utiliza $n$ e $n^{*}$ como sendo a proporção de bens não-comercializáveis nos países doméstico e estrangeiro, respectivamente. Assim, tem-se que os bens são ordenados tal que i $\epsilon$ $[0, n]$ são não comercializáveis, e i $\epsilon$ [n, 1) são comercializáveis no país doméstico, enquanto que i $€\left[1,1+n^{*}\right]$ são não comercializáveis, e i $\epsilon\left[1+n^{*}, 2\right]$ são comercializáveis no outro país. 
dor oferta trabalho, recebe lucro (quando proprietários de empresas nacionais) e detém moeda. A função consumo agregada é definida como sendo do tipo CES, combinando os consumos dos bens produzidos internamente e bens importados, da seguinte forma:

$$
C=\left[\int_{0}^{1} c_{H}(i)^{\frac{\mu-1}{\mu}} d i+\int_{+n^{*}}^{2} c_{F}(i)^{\frac{\mu-1}{\mu}} d i\right]^{\frac{\mu}{\mu-1}}
$$

Em que, $c_{H}(i)$ e $c_{F}(i)$ denotam, respectivamente, o consumo do bem $i$ doméstico e do bem $i$ estrangeiro, e $\mu$ representa a elasticidade de substituição entre os dois produtos, sendo a mesma maior do que um.

Ademais, cada país possui um contínuo de firmas, em que cada uma delas produz apenas um único produto. As firmas possuem distintos níveis de produtividade, sendo que esta é idêntica nos países doméstico e estrangeiro. Adicionalmente, as firmas que decidem exportar devem pagar um custo fixo de entrada no mercado internacional, que é uma função da taxa nominal de câmbio e do custo do trabalho no país estrangeiro ${ }^{3}\left(S W^{*} f^{*}\right)$.

Desde que a produtividade $(A)$ das firmas é distribuída no intervalo $\left[A_{\min }, A_{\max }\right]$, e como as mesmas para exportar devem pagar um custo fixo de entrada no mercado internacional, as firmas exportadoras possuem um nível de produtividade maior do que o das firmas não exportadoras. Em equilíbrio, apenas uma parte das firmas domésticas e uma parte das firmas estrangeiras conseguem adentrar no mercado internacional.

A firma exportadora decompõe seu lucro em proporções recebidas no mercado doméstico $\left[\pi_{H}(i)\right]$ e no mercado internacional $\left[\pi_{H}^{*}(i)\right]$, tal que:

$$
\begin{aligned}
& \pi_{H}(i)=p_{H}(i) c_{H}(i)-W L_{H}(i) \\
& \pi_{H}^{*}(i)=S p_{H}^{*}(i) c_{H}^{*}(i)-W L_{H^{*}}(i)-S W^{*} f^{*}
\end{aligned}
$$

\footnotetext{
3 No modelo, o autor não deixa explícito quais são estes trabalhos, apenas informa que os mesmos são necessários para exportar.
} 
Onde $p_{H}(i)$ e $p_{H}^{*}$ denotam, respectivamente, o preço do bem $i$ produzido internamente no país doméstico e do bem $i$ produzido internamente no país estrangeiro, sendo que $L_{H}(i)$ e $L_{H}{ }^{*}(i)$ representam, respectivamente, a oferta de mão de obra na produção do bem i nos mercados doméstico e estrangeiro.

No que tange à taxa de câmbio nominal, o seu equilíbrio pode ser derivado da pressuposição de que as estruturas dos países são simétricas. Com isso, a condição de equilíbrio do mercado de câmbio é a de que o excesso de oferta das duas moedas deve ser igual a zero em equilíbrio, ou seja, o valor de importação deve ser igual ao valor da receita de exportação. Ou seja, o equilíbrio da taxa de câmbio nominal é igual à razão das ofertas monetárias dos dois países.

Adicionalmente, o modelo assume que a oferta de moeda no país doméstico $(M)$ e estrangeiro $\left(M^{*}\right)$ segue uma distribuição log-normal, assim definida: $\log (M)=\bar{m}+\varepsilon$; onde $\bar{m}$ é uma constante e $\varepsilon$ é uma variável aleatória com distribuição normal, $N\left(-\frac{1}{2} \sigma_{m}^{2}, \sigma_{m}^{2}\right)$. Assim, tem-se que a incerteza (volatilidade) da taxa de câmbio resulta de um componente aleatório da oferta monetária do país doméstico. Neste caso, a volatilidade da taxa de câmbio é entendida como uma restrição ao comércio internacional, sendo a mesma derivada dos choques monetários que afetam os países.

Para analisar o impacto da volatilidade da taxa de câmbio nas decisões das firmas em entrar no mercado, além de avaliar esse impacto sobre a margem extensiva (número de produtos exportado pelas firmas) e margem intensiva (volume monetário exportado pelas firmas) do comércio internacional, deve-se considerar que os limites mínimos dos níveis de produtividade dos exportadores, $A(n)$ e $A^{*}\left(n^{*}\right)$, devem estar em níveis tal que a firma é indiferente entre produzir para o mercado doméstico ou para o mercado externo, resultando em que o lucro esperado da exportação da n-ésima firma doméstica deve ser nulo. ${ }^{4} \mathrm{O}$ mesmo vale para a n-ésima firma estrangeira $\left(\mathrm{n}^{*}\right){ }^{5}$

4 A distribuição do nível de produtividade das firmas é simétrica em ambos os países, doméstico e estrangeiro, e definida de forma exógena

5 Como mencionado anteriormente, Lin (2012) usa $n$ e $n^{*}$ para a representar a proporção de produtos não comercializáveis no país doméstico e país estrangeiro, mas que também se refere às firmas em cada país, pois considera que cada bem é produzido monopolisticamente por apenas uma firma. Consequentemente, pelo pressuposto do modelo o número de firmas que vende domesticamente é igual à proporção de produtos não comercializáveis. 
Da condição de lucro zero para a n-ésima firma doméstica, e com algumas substituições e manipulações algébricas, tem-se:

$$
E_{0}\left[U_{c}\left(S p_{H}^{*}(n)-\frac{W}{A(n)}\right) c_{H}^{*}(n)\right]=E_{0}\left[U_{c} S W^{*} f^{*}\right]
$$

Onde $E_{0}$ é o operador de esperança e $U_{c}$ é a utilidade marginal do consumo (a qual é utilizada como fator de desconto). A Equação (04) mostra que a receita líquida de exportação esperada para uma firma adicional $n$ deve ser igual ao valor esperado ao pagamento dos custos fixos de entrada desta firma.

De acordo com Lin (2012), considerando as funções demanda e salário, além das regras de formação de preços, equilíbrio da taxa de câmbio, e índice de preços agregados do modelo, ${ }^{6}$ a Equação (04) resulta em uma condição na qual um aumento na volatilidade cambial aumenta a quantidade de bens não comercializáveis, ou seja, a quantidade de bens comercializados é endógena neste modelo, sendo a mesma negativamente relacionada com a volatilidade cambial. Em outras palavras, a condição marginal oriunda de [04] requer maiores níveis de produtividade, de modo que uma menor variedade de bens é exportada quando a volatilidade cambial é elevada. A margem extensiva é, então, definida por (1-n).

O modelo mostra que uma elevação na incerteza (volatilidade) da taxa de câmbio, causa uma elevação do custo fixo de entrada no mercado internacional. O aumento do custo fixo, por sua vez, leva à saída do mercado internacional das firmas menos produtivas (aumentando o valor de $n$ ), tendo em vista que as mesmas não possuem níveis de produtividades suficientes para auferir renda positiva, devido à elevação do custo fixo.

Como consequência disto, o número de produtos exportados pelo país sofre uma redução, o que diminui a margem extensiva de comércio desse país.

6 Detalhes das descrições e derivações das equações e do modelo teórico podem ser encontrados em Lin (2012). 


\section{Estratégia Empírica}

\subsection{Equação Gravitacional}

Como o principal objetivo do presente trabalho consiste em analisar os efeitos da volatilidade da taxa de câmbio sobre a margem extensiva do comércio internacional, o modelo empírico a ser estimado será uma versão modificada da equação gravitacional de comércio (doravante equação gravitacional). Convém aqui frisar que a equação gravitacional vem sendo amplamente utilizada na literatura empírica desde meados dos anos sessenta, a partir do trabalho seminal de Tinbergen (1962). A relevância da equação gravitacional se deve em parte à sua fácil implementação, bem como ao seu relativo sucesso em explicar os fluxos comercias.

Sucintamente, o modelo gravitacional é a solução, em forma de equação reduzida, de um sistema de equilíbrio geral de comércio internacional em bens finais, o qual assume que o comércio entre dois países ocorre em função do seu tamanho, estágio de desenvolvimento, grau de abertura de mercado e proximidade. A fundamentação teórica da equação gravitacional pode ser encontrada em Anderson (1979), Helpman (1987), Bergstrand (1989), Feenstra et al. (1998), Anderson e van Wincoop (2001).

A formulação básica da equação gravitacional estabelece que o comércio entre dois parceiros comerciais será proporcional ao tamanho econômico dos países e inversamente proporcional à distância geográfica entre eles, ou seja:

$$
\mathrm{T}_{\mathrm{ij}}=\frac{\mathrm{Y}_{\mathrm{i}}^{\delta_{1}} \mathrm{Y}_{\mathrm{j}}^{\delta_{2}}}{\mathrm{D}_{\mathrm{ij}}^{\delta_{3}}}
$$

Onde: $T_{\mathrm{ij}}$ denota o comércio entre os países $i$ e $j$; $Y_{\mathrm{i}}$ e $\mathrm{Y}_{\mathrm{j}}$ representam os níveis de renda dos países $i$ e $j$, respectivamente; $D_{\mathrm{ij}}$ é a distância geográfica entre os países $i$ e $j$; $\delta_{\mathrm{i}}$ representam o impacto marginal das variáveis no fluxo de comércio.

$\mathrm{Na}$ forma logaritmizada, a equação gravitacional pode ser representada por: 


$$
\ln \mathrm{T}_{\mathrm{ij}}=\delta_{1} \ln \mathrm{Y}_{\mathrm{i}}+\delta_{2} \ln \mathrm{Y}_{\mathrm{j}}-\delta_{3} \ln \mathrm{D}_{\mathrm{ij}}
$$

$\mathrm{Ou}$, ainda:

$$
\mathrm{T}_{\mathrm{ij}}=\exp \left(\delta_{1} \ln \mathrm{Y}_{\mathrm{i}}+\delta_{2} \ln \mathrm{Y}_{\mathrm{j}}-\delta_{3} \ln \mathrm{D}_{\mathrm{ij}}\right)
$$

Conforme Frankel et al. (1995), a estrutura básica da equação gravitacional pode ser ampliada por meio da inclusão de $k$-3 variáveis de controle (representadas por $\theta$ ), em que estas identificam algumas características idiossincráticas das relações bilaterais de comércio, como, por exemplo, se os parceiros comerciais têm o mesmo idioma, possuem fronteiras comuns, acordos preferenciais, entre outras. Assim, tem-se:

$$
\mathrm{T}_{\mathrm{ij}}=\exp \left(\delta_{1} \ln \mathrm{Y}_{\mathrm{i}}+\delta_{2} \ln \mathrm{Y}_{\mathrm{j}}-\delta_{3} \ln \mathrm{D}_{\mathrm{ij}}+\sum_{\mathrm{i}=4}^{\mathrm{k}} \delta_{\mathrm{i}} \theta_{\mathrm{i}}\right)
$$

Para atingir o objetivo proposto no presente trabalho, além das variáveis de controle, adiciona-se no lado direito da equação gravitacional uma variável que representa a volatilidade da taxa de câmbio (V), assim como fizeram Bittencourt et al. (2007), Tenreyro (2007), Lin (2012), Sheldon et al. (2013), entre outros, resultando em:

$\mathrm{T}_{\mathrm{ij}}=\exp \left(\delta_{1} \ln \mathrm{Y}_{\mathrm{i}}+\delta_{2} \ln \mathrm{Y}_{\mathrm{j}}-\delta_{3} \ln \mathrm{D}_{\mathrm{ij}}+\sum_{\mathrm{i}=4}^{\mathrm{k}} \delta_{\mathrm{i}} \theta_{\mathrm{i}}+\delta_{\mathrm{k}+1} \mathrm{~V}_{\mathrm{ij}}\right)$

Assim, a equação gravitacional descrita na equação [09] será a estrutura a ser utilizada na formulação do modelo empírico, que será especificado na subseção 3.2 .

\subsection{Modelo Empírico, Variáveis e Fontes dos Dados}

No que tange à equação gravitacional apresentada na subseção anterior, um ponto importante a destacar é que a mesma é tradicionalmente utilizada na análise da margem intensiva do comércio internacional (volume monetário). Contudo, mais recentemente, a 
mesma também vem sendo empregada na análise da margem extensiva do comércio (número de produtos), como, por exemplo, nos trabalhos de Baldwin (2006), Dennis e Shepherd (2007), Pacheco e Pierola (2008), Shepherd (2008), Debaere e Mostashari (2010) e Lin (2012). Especificamente, no presente trabalho, a equação gravitacional a ser estimada possui a seguinte especificação:

$$
\begin{aligned}
\text { MEXT }_{\mathrm{ijt}}= & \exp \left(\alpha_{0}+\alpha_{\mathrm{t}}+\alpha_{\mathrm{ij}}+\beta_{1} \mathrm{VOL}_{\mathrm{ijt}}+\beta_{2} \mathrm{Ln} \mathrm{PIB}_{\mathrm{it}}+\beta_{3} \mathrm{Ln}_{\mathrm{PIB}}+\beta_{4} \mathrm{Ln}\right. \\
& \mathrm{OPEN}_{\mathrm{ij}}+\beta_{5} \operatorname{Ln}_{\mathrm{OPEN}} \mathrm{ij}+\beta_{6} \operatorname{LnDIST}_{\mathrm{ij}}+\beta_{7} \mathrm{APC}_{\mathrm{ijt}}+\beta_{8} \mathrm{FRONT}_{\mathrm{ij}} \\
& \left.+\beta_{9} \mathrm{IDIOMA}_{\mathrm{ij}}\right) \mathrm{u}_{\mathrm{ijt}}
\end{aligned}
$$

Onde: $\alpha_{\mathrm{t}}$ é o intercepto que capta o efeito do tempo sobre a margem extensiva do comércio internacional ${ }^{7} ; \alpha_{\mathrm{ij}}$ é o intercepto que capta o efeito da heterogeneidade não-observada, que está presente nas relações bilaterais de comércio; $\mathrm{u}_{\mathrm{ijt}}$ é o termo de erro idiossincrático. No que se segue da presente subseção, descrevem-se as variáveis dependente e explicativas que integram o modelo econométrico descrito na equação (10).

\subsubsection{Variável Dependente}

$\mathrm{MEXT}_{\mathrm{ijt}}$ representa a margem extensiva do comércio internacional entre os países $i$ (exportador) e $j$ (importador) no tempo $t$. Seguindo Bergin e Lin (2009), a margem extensiva do comércio internacional será mensurada por meio da contagem do número de "produtos" exportados pelo país $i$ para o país $j$ no tempo $t .^{8}$ Formalmente, o cômputo dessa variável será realizado da seguinte forma:

$$
D_{i j t}^{k}=\left\{\begin{array}{cc}
1 & \text { se } X_{i j t}^{k}>0 \\
0 & \text { se } X_{i j t}^{k}=0
\end{array}\right.
$$

7 No presente trabalho, o efeito do tempo será captado por meio de variáveis dicotômicas. Nesse caso, serão inseridas no modelo empírico um total de $(t-1)$ variáveis dicotômicas, onde $t$ denota o número de anos.

8 Humels e Klenow (2005) desenvolvem uma medida de mensuração da margem extensiva bem mais complexa da utilizada no presente trabalho. No entanto, os próprios autores admitem que essa variável pode ser mensurada de várias formas, sendo que dentre essas está a contagem do número de produtos exportados pelo país, tal como realizado no presente artigo. 


$$
\mathrm{MEXT}_{\mathrm{ijt}}=\sum_{\mathrm{k}=1}^{\mathrm{n}} \mathrm{D}_{\mathrm{ijt}}^{\mathrm{k}} \quad \mathrm{k}=(1,2, \ldots, \mathrm{n})
$$

Ou seja, primeiramente, cria-se uma variável dicotômica que terá valor igual a 1 quando a variável $X_{i j t}^{k}$ (que denota a exportação do "produto" $k$, do país $i$ para o país $j$, no ano $t$ ) for maior do que zero, e 0 em caso contrário. Em seguida, as variáveis dicotômicas criadas para os $k$ "produtos" serão somadas, obtendo-se, com isto, a margem extensiva bilateral ( $\mathrm{MEXT}_{\mathrm{ijt}}$ ), entre os países $i$ (exportador) e $j$ (importador) no ano $t$.

Devido à proxy adotada para a margem extensiva, é imprescindível fazer um breve comentário sobre o que está sendo considerado como "produto". Destaca-se que a base de dados ideal para a condução do presente trabalho seria ao nível da firma, pois, nessa situação, seria possível mapear todos os produtos exportados pelas firmas para os mais diferentes mercados. Contudo, como essa base não está disponível para este estudo, utilizar-se-á como proxy dos produtos, as categorias a seis dígitos do Sistema Harmonizado. Dessa forma, o número total de produtos ${ }^{9}$ que o país $i$ pode exportar para o $j$-ésimo parceiro comercial, no ano $t$, será igual a 5.038 .

Neste artigo, utilizou-se a metodologia descrita na presente subseção para a mensuração da margem extensiva do comércio internacional de 54 países para o período compreendido entre 1995 a 2009, cujos dados estão reportados na Tabela 1. Observa-se que os Estados Unidos, a Alemanha e a Itália são os países que possuem as maiores margens extensivas do comércio, tendo em vista que os mesmos conseguem penetrar no mercado dos parceiros comerciais, em média, 3.271, 3.062 e 2.665 produtos, respectivamente. No outro extremo, Senegal, Jamaica e Camarões são os países que possuem as menores margens extensivas, sendo que esses países penetram, em média, apenas 38, 37 e 32 produtos, respectivamente, nos mercados dos

\footnotetext{
9 É importante ressaltar que a utilização desta base de dados possui, pelo menos, dois problemas potenciais. O primeiro, conforme Baldwin (2006), refere-se ao fato de que os dados a seis dígitos, apesar de serem extremamente desagregados, não mensuram o número total de produtos individuais exportados pelo país, tendo em vista que um grande número de produtos pode estar compreendido sob uma mesma categoria. O segundo problema refere-se ao fato de que a base de dados computa apenas os fluxos comerciais acima de US $\$ 1.000$, sendo assim, o número de categorias exportadas pelos países pode ser mais elevado do que o reportado no presente estudo.
} 
seus parceiros comerciais. Especificamente, o Brasil ocupa o décimo nono lugar, inserindo, em média, 1.013 produtos nos mercados dos parceiros comerciais. Outro ponto importante a destacar nos dados reportados na Tabela 1 é que diversos países apresentam um valor mínimo da margem extensiva igual a zero; isso significa que esses países não realizaram comércio com todos os países considerados no estudo.

Tabela 1 - Estatística descritiva da margem extensiva do comércio internacional, por país (os valores se referem ao período de 1995 a 2009).

\begin{tabular}{|c|c|c|c|c|c|}
\hline Posição & País exportador & Média & Desvio-padrão & Mínimo & Máximo \\
\hline 1 & Estados Unidos & 3.271 & 986 & 260 & 4.938 \\
\hline 2 & Alemanha & 3.062 & 1.215 & 493 & 4.883 \\
\hline 3 & Itália & 2.665 & 1.096 & 227 & 4.692 \\
\hline 4 & França & 2.591 & 1.240 & 174 & 4.821 \\
\hline 5 & Reino Unido & 2.558 & 1.280 & 205 & 4.684 \\
\hline 6 & China & 2.410 & 1.031 & 202 & 4.401 \\
\hline 7 & Holanda & 2.094 & 1.256 & 149 & 4.791 \\
\hline 8 & Espanha & 2.030 & 995 & 130 & 4.523 \\
\hline 9 & Bélgica/Luxemburgo & 1.930 & 1.180 & 90 & 4.809 \\
\hline 10 & Japão & 1.803 & 1.111 & 132 & 4.296 \\
\hline 11 & Suíça & 1.642 & 1.007 & 94 & 4.346 \\
\hline 12 & Suécia & 1.424 & 1.021 & 46 & 4.198 \\
\hline 13 & Índia & 1.385 & 897 & 36 & 3.842 \\
\hline 14 & Coréia do Sul & 1.373 & 896 & 110 & 3.925 \\
\hline 15 & Áustria & 1.275 & 1.064 & 0 & 4.217 \\
\hline 16 & Dinamarca & 1.267 & 996 & 54 & 3.853 \\
\hline 17 & Hong Kong & 1.245 & 819 & 64 & 4.511 \\
\hline 18 & Canadá & 1.207 & 794 & 35 & 4.565 \\
\hline 19 & Brasil & 1.013 & 726 & 0 & 3.084 \\
\hline 20 & Cingapura & 943 & 999 & 0 & 4.517 \\
\hline 21 & Austrália & 927 & 975 & 8 & 4.156 \\
\hline 22 & México & 884 & 786 & 0 & 4.208 \\
\hline 23 & Turquia & 874 & 773 & 3 & 3.168 \\
\hline 24 & Malásia & 850 & 824 & 4 & 3.980 \\
\hline 25 & Indonésia & 844 & 729 & 0 & 3.356 \\
\hline 26 & Finlândia & 832 & 721 & 17 & 3.303 \\
\hline 27 & Polônia & 776 & 857 & 2 & 3.812 \\
\hline 28 & Noruega & 743 & 751 & 4 & 3.520 \\
\hline 29 & Portugal & 707 & 717 & 9 & 3.719 \\
\hline
\end{tabular}


Tabela 1 - Estatística descritiva da margem extensiva do comércio internacional, por país (os valores se referem ao período de 1995 a 2009). (Continuação)

\begin{tabular}{lcllll}
\hline 30 & Irlanda & 648 & 651 & 14 & 3.656 \\
31 & Hungria & 611 & 681 & 1 & 3.064 \\
32 & Argentina & 525 & 624 & 7 & 2.782 \\
33 & Grécia & 453 & 501 & 1 & 2.158 \\
34 & Rússia & 444 & 450 & 0 & 2.099 \\
35 & Nova Zelândia & 435 & 571 & 1 & 3.308 \\
36 & Chile & 349 & 408 & 0 & 1.948 \\
37 & Colômbia & 328 & 476 & 1 & 2.318 \\
38 & Peru & 230 & 287 & 0 & 1.494 \\
39 & Guatemala & 193 & 422 & 0 & 2.313 \\
40 & Costa Rica & 188 & 304 & 0 & 1.524 \\
41 & Tunísia & 184 & 309 & 0 & 1.949 \\
42 & Venezuela & 160 & 270 & 0 & 2.018 \\
43 & Equador & 133 & 189 & 0 & 1.152 \\
44 & El Salvador & 124 & 294 & 0 & 1.632 \\
45 & Uruguai & 122 & 186 & 0 & 1.454 \\
46 & Honduras & 95 & 201 & 0 & 1.172 \\
47 & Costa do Marfim & 60 & 100 & 0 & 604 \\
48 & Nicarágua & 53 & 114 & 0 & 645 \\
49 & Nigéria & 50 & 79 & 0 & 438 \\
50 & Ghana & 49 & 71 & 0 & 357 \\
51 & Paraguai & 44 & 73 & 0 & 522 \\
52 & Senegal & 38 & 73 & 0 & 591 \\
53 & Jamaica & 37 & 92 & 0 & 747 \\
54 & Camarões & 32 & 49 & 0 & 348 \\
\hline & & & &
\end{tabular}

Fonte: Base de dados.

\subsubsection{Variáveis Explicativas}

$\mathrm{VOL}_{\mathrm{ijt}}$ denota uma medida de volatilidade da taxa de câmbio entre os países $i$ e $j$ no tempo $t$. Sheldon et al. (2012) advogam que na construção da variável que mensura a volatilidade da taxa de câmbio existe um grau de arbitrariedade envolvido, tanto no tocante à medida que se deve utilizar quanto sobre qual o período de tempo que a mesma deve levar em consideração. Sheldon et al. (ibidem) argumentam que os resultados são geralmente robustos no que tange ao período de tempo utilizado para o cálculo da volatilidade, mas a 
questão mais importante recai sobre qual medida de volatilidade se deve utilizar. Sendo assim, no presente trabalho, o cálculo da volatilidade da taxa de câmbio será para o período de um ano, seguindo Clark et al. (2004), Tenreyro (2007) e Álvarez et al. (2009), e para se obter uma maior robustez nos resultados, serão utilizadas três medidas da volatilidade da taxa de câmbio.

A primeira delas, seguindo Frankel e Wei (1993), Dell'Ariccia (1998), Rose (2000), Clark et al. (2004), Bittencourt et al. (2007), Tenreyro (2007), Álvarez et al. (2009), entre outros, ${ }^{10}$ será o desvio-padrão (desv.pad.) da primeira diferença do logaritmo natural da taxa de câmbio bilateral (mensal) entre os países $i$ e $j$, no ano $t$, ou seja:

$S_{\mathrm{ijt}}=\operatorname{desv}$. pad. $\left[\ln \left(\mathrm{e}_{\mathrm{ijt}, \mathrm{m}}\right)-\ln \left(\mathrm{e}_{\mathrm{ijt}, \mathrm{m}-1}\right)\right], \quad(\mathrm{m}=1,2, \ldots, 12$.

Seguindo Araújo (2011), a segunda medida de volatilidade será o coeficiente de variação da taxa de câmbio bilateral (mensal) entre os países $i$ e $j$ no ano $t$, isto é:

$\mathrm{W}_{\mathrm{ijt}}=\sqrt{\left(\mathrm{e}_{\mathrm{ijt}, \mathrm{m}}-\overline{\mathrm{e}}_{\mathrm{ijt}, \mathrm{m}}\right)^{2}} / \overline{\mathrm{e}}_{\mathrm{ijt}, \mathrm{m}}, \quad(\mathrm{m}=1,2, \ldots, 12$.

Por fim, inspirada em Hondroyiannis et al. (2005), a terceira medida de volatilidade será a diferença relativa entre o valor máximo e mínimo da taxa de câmbio bilateral (mensal) entre os países $i$ e $j$ no ano $t$, isto é:

$\mathrm{Z}_{\mathrm{ijt}}=\left(\mathrm{e}_{\mathrm{ijt}, \mathrm{m}}^{\mathrm{Max}}-\mathrm{e}_{\mathrm{ijt}, \mathrm{m}}^{\mathrm{Min}}\right) / \mathrm{e}_{\mathrm{ijt}, \mathrm{m}}^{\mathrm{Min}}, \quad(\mathrm{m}=1,2, \ldots, 12$.

Um ponto importante a destacar no tocante à mensuração da volatilidade diz respeito à utilização da taxa real de câmbio, em detrimento da taxa nominal. Clark et al. (2004) advogam que, como as taxas nominal e real possuem uma elevada correlação, a utilização de uma ou da outra não prejudica a mensuração da volatilidade e, consequentemente, os resultados econométricos; fato que também

${ }^{10}$ Bahmani-Oskooee e Hegerty (2007) destacam que essa medida de volatilidade é a mais utilizada na literatura empírica; numa extensa revisão acerca do tema, os autores contaram um total de 32 trabalhos que a utilizam. 
fora observado em Dell'Ariccia (1998). Dessa forma, no presente trabalho, devido ao acesso à base de dados, utilizou-se a taxa de câmbio real ${ }^{11}$ na mensuração da volatilidade. Estudos mais recentes que também utilizaram a taxa real de câmbio foram: Arize et al. (2005), Hwang e Lee (2005), Bittencourt et al. (2007), Álvarez et al. (2009) e Sheldon et al. (2013).

Outro ponto importante a ressaltar é que pode haver uma direção oposta de causalidade entre a volatilidade da taxa real de câmbio e o comércio internacional, pois para Mundell (1961) os fluxos de comércio tendem a estabilizar as flutuações da taxa real de câmbio, reduzindo, com isso, a sua volatilidade. Caso isso realmente ocorra, no modelo empírico descrito na equação [10], a volatilidade da taxa de câmbio passa a ter uma natureza endógena, e os parâmetros obtidos na estimação serão inconsistentes, e o modelo deve ser estimado com variável instrumental (Wooldridge, 2002). Assim, para corrigir o referido problema, Mukherjee e Pozo (2011) utilizam a volatilidade da taxa real de câmbio no período $t$ - 1 como variável instrumental da volatilidade da taxa real de câmbio do período $t$. Ressalta-se que esta estratégia também será adotada no presente estudo.

As demais variáveis explicativas que integram o modelo empírico são tradicionalmente incorporadas no modelo gravitacional de comércio, e podem ser assim definidas: $L n \mathrm{PIB}_{i t}$ e $\mathrm{Ln} \mathrm{PIB}_{\mathrm{jt}}$ denotam, respectivamente, os logaritmos naturais do Produto Interno Bruto dos países $i$ e $j$, no tempo $t$. Conforme Azevedo et al. (2006), estas variáveis representam uma proxy para a renda dos países.

Por conta disso, é razoável supor que quanto maior o nível de renda dos países, maior será a quantidade demandada por produtos e, ademais, está implícita a ideia de que quanto maior a renda de uma nação, maior será a diversidade de mercadorias a serem ofertadas, como mostram Hummels e Klenow (2005). Assim, espera-se que os coeficientes associados a tais variáveis tenham sinais positivos $\left(\beta_{2}>\right.$ 0 e $\beta_{3}>0$ ).

\footnotetext{
${ }^{11}$ Mas cabe também destacar que existe uma grande controvérsia sobre a utilização da taxa de câmbio real na mensuração da volatilidade pelos seguintes motivos: (i) não se sabe ao certo de que forma a inflação utilizada é mensurada; (ii) muitos países não utilizam as mesmas cestas de bens no cômputo da inflação; e (iii) mudam a composição destas cestas de bens, trazendo maiores dificuldades em se utilizar a taxa de câmbio real (McKenzie et al., 1998).
} 


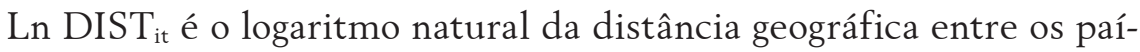
ses $i$ e $j$. Conforme Nilsson (1999) esta variável configura-se como uma proxy dos custos de transporte. Dessa forma, a literatura mostra que os países tendem a comercializar relativamente menos com os parceiros comerciais mais longínquos. Assim, se espera que o coeficiente associado à referida variável apresente sinal negativo $\left(\beta_{8}<0\right)$.

Ln OPEN $\mathrm{it}_{\mathrm{it}}$ e Ln OPEN $\mathrm{j}_{\mathrm{jt}}$ denotam, respectivamente, os logaritmos naturais do grau de abertura ao comércio internacional ${ }^{12}$ dos países $i$ e $j$, no tempo $t$. Estas são variáveis de controle que partem da ideia de que o grau de abertura dos países tende a facilitar a penetração dos produtos importados no mercado doméstico do país. Assim, assumese que os coeficientes associados às referidas variáveis serão positivos $\left(\beta_{4}>0\right.$ e $\left.\beta_{5}>0\right)$.

$\mathrm{APC}_{\mathrm{ijt}}$ é uma variável que assume valor igual a 1 quando os países $i$ e $j$ possuem acordo preferencial de comércio e 0 em caso contrário. Acredita-se que a firmação de um acordo preferencial de comércio mitigue os custos fixos de entrada nos mercados dos parceiros comerciais pertencentes ao bloco. Portanto, se espera que a variável APC tenha um efeito positivo sobre a margem extensiva do comércio internacional $\left(\beta_{9}>0\right)$.

$\mathrm{FRONT}_{\mathrm{ij}}$ é uma variável que assume valor igual a 1 quando os países $i$ e $j$ são adjacentes e 0 em caso contrário. A literatura aponta que quando dois parceiros são adjacentes, os custos de transporte são relativamente menores, estimulando os fluxos comerciais entre eles. Assim, esperase que o coeficiente associado à referida variável apresente um sinal positivo $\left(\beta_{8}>0\right)$.

IDIOMA $_{\mathrm{ij}}$ é uma variável com valor igual a 1 quando os países $i$ e $j$ possuem o mesmo idioma e 0 em caso contrário. Andersson (2007) destaca que quando dois países possuem o mesmo idioma, os custos de comunicação tendem a ser relativamente menores, estimulando o comércio entre os países. Portanto, conjectura-se que o coeficiente associado à referida variável tenha um sinal positivo $\left(\beta_{9}>0\right)$.

A base de dados utilizada nas estimações compreende os fluxos bilaterais de comércio entre 54 países, durante o período compreendido 12 O grau de abertura dos países foi calculado da seguinte forma: Open $=($ exportação + im-
portação) $/$ PIB

Estud. Econ., São Paulo, vol.44, n.4, p.815-845, out.-dez. 2014 
entre 1995 a 2009. Assim, da combinação das observações de cross section $(\mathrm{N}=2.862)$ com as observações de série de tempo $(\mathrm{T}=15)$, se dispõe de um painel de dados com 42.930 observações $(\mathrm{N} \times \mathrm{T}=$ 42.930). As estatísticas descritivas das variáveis que integram esta base de dados podem ser obtidas no Apêndice I.

Os dados utilizados no presente estudo são procedentes de distintas fontes. No caso da variável dependente, os dados utilizados são oriundos da base BACI, que é publicada pelo Centre D'Estudes Prospectives et d'Informations Internationales (CEPII). No tocante às variáveis explicativas: as taxas reais de câmbios dos países foram obtidas junto à base de dados do Departamento de Agricultura dos Estados Unidos (United States Department of Agriculture USDA). Os PIB's dos países foram obtidos junto ao Fundo Monetário Internacional (FMI). O grau de abertura ao comércio foi obtido junto à base de dados do Penn World Table 7.0. As distâncias geográficas entre os países, assim como as variáveis dicotômicas, foram obtidas junto ao Centre d'Etudes Prospectives et d'Informations Internationales (CEPII).

\subsection{Procedimento de Estimação dos Parâmetros}

Conforme a literatura, a prática tradicional de estimação do modelo gravitacional de comércio consiste em logaritmizar ambos os lados do modelo e estimá-lo por Mínimos Quadrados Ordinários (MQO). Contudo, no presente trabalho, seguindo Santos Silva e Tenreyro (2006), a equação gravitacional será estimada pela técnica econométrica Poisson Pseudo Maximum Likelihood (PPML). Destaca-se que com a utilização da mesma, a equação gravitacional será estimada na sua forma não linear, com a variável dependente em nível, assim como especificada na Equação (10).

Optou-se por estimar a equação gravitacional pela técnica Poisson Pseudo Maximum Likelihood (PPML) por três motivos. Em primeiro lugar, é sabido que o logaritmo natural não é definido para o valor zero. Especificamente, isso pode constituir-se em um problema, pois, como a base de dados utilizada no presente estudo compreende os fluxos bilaterais de comércio entre 54 países, alguns pares de países não realizaram comércio entre si em algum ponto no tempo, o que ocasiona alguns fluxos comerciais nulos. Diante disto, a variável de- 
pendente $\mathrm{MEXT}_{\mathrm{ijt}}$ possui valor zero para 815 observações; as quais serão excluídas das estimações, caso seja realizada a logaritmização das variáveis. Westerlund e Wilhelmsson (2011) destacam que a exclusão dessas variáveis poderá causar um viés de seleção na amostra, causando uma inconsistência nos parâmetros obtidos nas estimações.

Em segundo lugar, a desigualdade de Jensen afirma que $\mathrm{E}(\ln \mathrm{y}) \neq$ $\ln \mathrm{E}(\mathrm{y})$; isto é, o valor esperado do logaritmo natural de uma variável aleatória é distinto do logaritmo natural do seu valor esperado. Conforme Santos Silva e Tenreyro (2006), uma importante implicação da desigualdade de Jensen é que os parâmetros obtidos por MQO, com as variáveis logaritmizadas, são inconsistentes caso o termo de erro idiossincrático seja heterocedástico.

Em terceiro lugar, a variável dependente (MEXT) do modelo descrito na equação (10) é constituída por valores discretos. Nessa situação, conforme Cameron e Trivedi (2005), a distribuição de Poisson tem um melhor ajuste aos dados do que a distribuição normal, lembrando que essa última é assumida no momento da estimação do modelo MQO.

Destaca-se ainda que, como ressaltado na apresentação do modelo econométrico (subseção 3.2), considerou-se entre as variáveis explicativas a heterogeneidade não observada $\left(\alpha_{\mathrm{ij}}\right)$. Conforme Cheng e Wall (2005), a heterogeneidade não observada pode estar associada aos fatores culturais, políticos, étnicos ou geográficos, sendo que, na sua presença, um país pode exportar um número diferente de produtos para outros dois parceiros comerciais, mesmo que esses dois parceiros comerciais tenham o mesmo PIB e sejam equidistantes do país exportador. Dessa forma, sob o ponto de vista econométrico, a heterogeneidade não observada pode causar uma inconsistência nos resultados, caso a mesma não seja corretamente controlada.

Conforme Wooldridge (2002), a heterogeneidade pode ser controlada por meio das técnicas econométricas de dados em painel. Destaca-se que, caso a heterogeneidade não observada não seja correlacionada com as variáveis explicativas, o modelo pode ser estimado tanto na forma Pooled quanto com Efeitos-Aleatórios, mas estimações mais eficientes serão obtidas por meio do modelo com Efeitos Aleatórios. Por outro lado, quando a heterogeneidade não observada é correlacionada com as variáveis explicativas, o modelo deve ser 
estimado com Efeitos-Fixos. Especificamente, no presente trabalho, o modelo econométrico descrito em (10) será estimado na forma Pooled, com Efeitos-Aleatórios e com Efeitos-Fixos. Destaca-se que a estimação por diferentes técnicas de painel torna-se importante, pois possibilita identificar de que forma os resultados se modificam conforme o tratamento dado à heterogeneidade não observada.

Outra complicação encontrada na estimação do modelo econométrico está relacionada ao pressuposto básico da distribuição de Poisson. Destaca-se que este pressuposto assume a igualdade entre a média e a variância (propriedade de equidispersão) da distribuição, mas, com uma rápida inspeção na estatística descritiva reportada no Apêndice I, é possível verificar que a variável dependente do modelo econométrico (MEXT) possui média e variância extremamente distintas, violando o referido pressuposto. ${ }^{13}$ No entanto, a violação do pressuposto básico da distribuição de Poisson não altera a consistência dos resultados obtidos (Cameron e Trivedi, 2005), mas para obter uma medida mais confiável do erro-padrão e, consequentemente, da significância estatística do parâmetro, o modelo deve ser estimado com variância robusta. Assim, no presente artigo, o erro-padrão será estimado por bootstrap (com 400 replicações). ${ }^{14}$

\section{Resultados e Discussões}

Na presente seção analisa-se o efeito da volatilidade da taxa de câmbio sobre a margem extensiva da pauta de exportação, os quais estão reportados na Tabela 2 .

Nessa tabela encontram-se as estimações do modelo PPML na forma Pooled, com Efeitos Aleatórios e com Efeitos-Fixos. Como o modelo PPML Pooled não trata adequadamente as heterogeneidades não observadas dos países, os resultados obtidos deste modelo serão inconsistentes, sendo assim, os modelos PPML com Efeitos Aleatórios e PPML com Efeitos Fixos serão utilizados como referência. Ademais, a estatística de Wald, reportada para todos os modelos

\footnotetext{
${ }^{13}$ A desigualdade entre a média e a variância foi comprovada por meio do teste sobredispersão proposto por Cameron e Trivedi (2005).

14 Cameron e Trivedi (2009, p. 419) sugerem que 400 replicações fornecem uma estimativa confiável dos erros padrões.
} 
estimados, possibilita refutar a hipótese nula de independência da média condicional, indicando que as variáveis explicativas possuem efeitos estatisticamente significativos sobre a margem extensiva do comércio internacional.

Com respeito aos resultados obtidos, destaca-se que, de maneira geral, a maior parte das variáveis é estatisticamente significativa e apresenta o sinal coerente com a literatura empírica. Outro fato importante a ressaltar é a robustez dos resultados, haja vista que os resultados obtidos pelos modelos com Efeitos-Aleatórios e com Efeitos-Fixos são praticamente idênticos, tanto em termos de magnitude dos parâmetros quanto em nível de significância. ${ }^{15}$

Nota-se que em todas as estimações o logaritmo natural do PIB do país exportador ( $\mathrm{Ln} \mathrm{PIB}_{\mathrm{it}}$ ) tem um efeito positivo sobre a margem extensiva do comércio internacional, o que está em conformidade com a teoria. Analisando este resultado sob a ótica do modelo teórico de Lin (2012), acredita-se que existe uma correlação positiva entre o PIB dos países e o nível de produtividade das firmas domésticas, ou seja, países com PIB mais elevados tendem a possuir firmas relativamente mais produtivas. Em consequência disso, as firmas oriundas desses países conseguem suplantar mais facilmente os custos fixos de entrada nos mercados dos parceiros comerciais, fazendo com que, em nível agregado, o país com maior PIB tenha uma maior margem extensiva do comércio. Outros estudos encontrados na literatura, como Hummels e Klenow (2005), Brenton e Newfarmer (2007) e Pacheco e Pierola (2008), por exemplo, também evidenciaram que os países com maiores níveis de renda exportam um número maior de produtos.

15 Todas as estimações foram realizadas pelo pacote estatístico Stata 11. 
Tabela 2 - Efeitos da volatilidade da taxa de câmbio sobre a margem extensiva do comércio internacional- resultados obtidos a partir da estimação do modelo gravitacional de comércio.

\begin{tabular}{|c|c|c|c|}
\hline \multicolumn{4}{|l|}{ (I) $\mathrm{VOL}_{i j t}=\mathrm{S}_{i j t}$} \\
\hline \multirow{2}{*}{ Variável explicativa } & \multicolumn{3}{|c|}{ Coeficiente } \\
\hline & Pooled & Efeitos Aleatórios & Efeitos Fixos \\
\hline$S_{i j t}$ & $\begin{array}{l}-1,191 \\
{[0,000]}\end{array}$ & $\begin{array}{c}-0,148 \\
{[0,001]}\end{array}$ & $\begin{array}{l}-0,151 \\
{[0,003]}\end{array}$ \\
\hline $\operatorname{LnPIB}_{i t}$ & $\begin{array}{c}0,646 \\
{[0,000]}\end{array}$ & $\begin{array}{c}0,533 \\
{[0,000]}\end{array}$ & $\begin{array}{c}0,528 \\
{[0,000]}\end{array}$ \\
\hline $\operatorname{Ln} \mathrm{PIB}_{j t}$ & $\begin{array}{c}0,284 \\
{[0,000]}\end{array}$ & $\begin{array}{c}0,317 \\
{[0,000]}\end{array}$ & $\begin{array}{c}0,317 \\
{[0,000]}\end{array}$ \\
\hline Ln OPEN $_{i t}$ & $\begin{array}{c}0,571 \\
{[0,000]}\end{array}$ & $\begin{array}{c}-0,007 \\
{[0,728]}\end{array}$ & $\begin{array}{l}-0,007 \\
{[0,758]}\end{array}$ \\
\hline $\operatorname{Ln}_{\mathrm{OPEN}}{ }_{\mathrm{ft}}$ & $\begin{array}{c}0,151 \\
{[0,000]}\end{array}$ & $\begin{array}{c}0,040 \\
{[0,084]}\end{array}$ & $\begin{array}{c}0,040 \\
{[0,086]}\end{array}$ \\
\hline $\operatorname{Ln} \mathrm{DIST}_{i j}$ & $\begin{array}{c}-0,336 \\
{[0,000]}\end{array}$ & $\begin{array}{c}-0,567 \\
{[0,000]}\end{array}$ & - \\
\hline $\mathrm{APC}_{i j t}$ & $\begin{array}{c}0,351 \\
{[0,000]}\end{array}$ & $\begin{array}{c}0,002 \\
{[0,877]}\end{array}$ & - \\
\hline $\mathrm{FRONT}_{i j}$ & $\begin{array}{l}-0,152 \\
{[0,000]}\end{array}$ & $\begin{array}{c}0,081 \\
{[0,234]}\end{array}$ & - \\
\hline$I_{D I O M A}$ & $\begin{array}{c}0,317 \\
{[0,000]}\end{array}$ & $\begin{array}{c}0,323 \\
{[0,000]}\end{array}$ & - \\
\hline Número de observações & 42.930 & 42.930 & 42.930 \\
\hline Estatística de Wald & $\begin{array}{c}98.775,57 \\
{[0,000]}\end{array}$ & $\begin{array}{c}3.288,23 \\
{[0,000]}\end{array}$ & $\begin{array}{c}1.975,06 \\
{[0,000]}\end{array}$ \\
\hline Pseudo $R^{2}$ & 0,77 & - & - \\
\hline Controle do tempo $\left(\alpha_{t}\right)$ & Sim & Sim & Sim \\
\hline Controle da heterogeneidade $\left(\alpha_{i j}\right)$ & Não & Sim & Sim \\
\hline \multicolumn{4}{|l|}{ (II) $\mathrm{VOL}_{i j t}=\mathrm{W}_{i j t}$} \\
\hline \multirow{2}{*}{ Variável explicativa } & \multicolumn{3}{|c|}{ Coeficiente } \\
\hline & Pooled & Efeitos Aleatórios & Efeitos Fixos \\
\hline$W_{i j t}$ & $\begin{array}{l}-1,154 \\
{[0,000]}\end{array}$ & $\begin{array}{l}-0,122 \\
{[0,001]}\end{array}$ & $\begin{array}{l}-0,123 \\
{[0,001]}\end{array}$ \\
\hline $\operatorname{Ln} \mathrm{PIB}_{i t}$ & $\begin{array}{c}0,645 \\
{[0,000]}\end{array}$ & $\begin{array}{c}0,535 \\
{[0,000]}\end{array}$ & $\begin{array}{c}0,530 \\
{[0,000]}\end{array}$ \\
\hline $\operatorname{LnPIB}_{j t}$ & $\begin{array}{c}0,284 \\
{[0,000]}\end{array}$ & $\begin{array}{c}0,318 \\
{[0,000]}\end{array}$ & $\begin{array}{c}0,317 \\
{[0,000]}\end{array}$ \\
\hline Ln OPEN $_{i t}$ & $\begin{array}{c}0,569 \\
{[0,000]}\end{array}$ & $\begin{array}{l}-0,007 \\
{[0,764]}\end{array}$ & $\begin{array}{c}-0,006 \\
{[0,790]}\end{array}$ \\
\hline $\operatorname{Ln}_{\text {OPEN }}{ }_{j t}$ & $\begin{array}{c}0,150 \\
{[0,000]}\end{array}$ & $\begin{array}{c}0,040 \\
{[0,087]}\end{array}$ & $\begin{array}{c}0,040 \\
{[0,093]}\end{array}$ \\
\hline $\operatorname{Ln~DIST}_{i j}$ & $\begin{array}{c}-0,333 \\
{[0,000]}\end{array}$ & $\begin{array}{c}-0,567 \\
{[0,000]}\end{array}$ & - \\
\hline $\mathrm{APC}_{i j t}$ & $\begin{array}{c}0,345 \\
{[0,000]}\end{array}$ & $\begin{array}{c}0,002 \\
{[0,852]}\end{array}$ & - \\
\hline $\mathrm{FRONT}_{i j}$ & $\begin{array}{c}-0,152 \\
{[0,000]}\end{array}$ & $\begin{array}{c}0,081 \\
{[0,207]}\end{array}$ & - \\
\hline$I^{D I O M A} A_{i j}$ & $\begin{array}{c}0,315 \\
{[0,000]}\end{array}$ & $\begin{array}{c}0,324 \\
{[0,000]}\end{array}$ & - \\
\hline Número de observações & 42.930 & 42.930 & 42.930 \\
\hline Estatística de Wald & $80.349,77$ & $3.372,01$ & $2.499,84$ \\
\hline Pseudo $R^{2}$ & 0,77 & - & - \\
\hline Controle do tempo $\left(\alpha_{t}\right)$ & Sim & Sim & Sim \\
\hline Controle da heterogeneidade $\left(\alpha_{i j}\right)$ & Não & Sim & Sim \\
\hline
\end{tabular}


Tabela 2 - Efeitos da volatilidade da taxa de câmbio sobre a margem extensiva do comércio internacional- resultados obtidos a partir da estimação do modelo gravitacional de comércio. (Continuação)

\begin{tabular}{|c|c|c|c|}
\hline \multicolumn{4}{|l|}{ (III) $\mathrm{VOL}_{i j t}=\mathrm{Z}_{j \mathrm{jt}}$} \\
\hline \multirow{2}{*}{ Variável explicativa } & \multicolumn{3}{|c|}{ Coeficiente } \\
\hline & Pooled & Efeitos Aleatórios & Efeitos Fixos \\
\hline$Z_{i j t}$ & $\begin{array}{l}-0,278 \\
{[0,000]}\end{array}$ & $\begin{array}{l}-0,035 \\
{[0,000]}\end{array}$ & $\begin{array}{l}-0,035 \\
{[0,000]}\end{array}$ \\
\hline $\operatorname{Ln} \mathrm{PIB}_{i t}$ & $\begin{array}{c}0,646 \\
{[0,000]}\end{array}$ & $\begin{array}{c}0,534 \\
{[0,000]}\end{array}$ & $\begin{array}{c}0,529 \\
{[0,000]}\end{array}$ \\
\hline $\operatorname{Ln} \mathrm{PIB}_{j t}$ & $\begin{array}{c}0,284 \\
{[0,000]}\end{array}$ & $\begin{array}{c}0,317 \\
{[0,000]}\end{array}$ & $\begin{array}{c}0,316 \\
{[0,000]}\end{array}$ \\
\hline $\operatorname{Ln}_{\text {OPEN }}{ }_{i t}$ & $\begin{array}{c}0,570 \\
{[0,000]}\end{array}$ & $\begin{array}{l}-0,006 \\
{[0,772]}\end{array}$ & $\begin{array}{l}-0,006 \\
{[0,782]}\end{array}$ \\
\hline $\operatorname{Ln~OPEN~}_{j t}$ & $\begin{array}{c}0,150 \\
{[0,000]}\end{array}$ & $\begin{array}{c}0,040 \\
{[0,076]}\end{array}$ & $\begin{array}{c}0,040 \\
{[0,070]}\end{array}$ \\
\hline $\operatorname{Ln~DIST}_{i j}$ & $\begin{array}{c}-0,334 \\
{[0,000]}\end{array}$ & $\begin{array}{l}-0,567 \\
{[0,000]}\end{array}$ & - \\
\hline $\mathrm{APC}_{i j t}$ & $\begin{array}{c}0,347 \\
{[0,000]}\end{array}$ & $\begin{array}{c}0,002 \\
{[0,881]}\end{array}$ & - \\
\hline $\mathrm{FRONT}_{i j}$ & $\begin{array}{c}-0,152 \\
{[0,000]}\end{array}$ & $\begin{array}{c}0,081 \\
{[0,241]}\end{array}$ & - \\
\hline $\mathrm{IDIOMA}_{i j}$ & $\begin{array}{c}0,315 \\
{[0,000]}\end{array}$ & $\begin{array}{c}0,323 \\
{[0,000]}\end{array}$ & - \\
\hline Número de observações & 42.930 & 42.930 & 42.930 \\
\hline Estatística de Wald & $\begin{array}{c}95.205,09 \\
{[0,000]}\end{array}$ & $\begin{array}{c}3.301,75 \\
{[0,000]}\end{array}$ & $\begin{array}{c}2.019,24 \\
{[0,000]}\end{array}$ \\
\hline Pseudo $R^{2}$ & 0,77 & - & - \\
\hline Controle do tempo $\left(\alpha_{t}\right)$ & Sim & Sim & Sim \\
\hline Controle da heterogeneidade $\left(\alpha_{i j}\right)$ & Não & Sim & Sim \\
\hline
\end{tabular}

Fonte: Dados da pesquisa.

Nota: Entre colchetes está reportado o p-valor, que fora obtido por bootstrap (com 400 replicações).

Além do PIB do país exportador, nota-se que o PIB do país importador $\left(\mathrm{Ln} \mathrm{PIB}_{\mathrm{jt}}\right.$ ) também tem um efeito positivo sobre a margem extensiva do comércio. Acredita-se que o aumento do nível de renda do parceiro comercial, ocorre em paralelo a um aumento da demanda por produtos importados, com isto, as firmas estrangeiras conseguem penetrar um número maior de produtos no mercado do parceiro comercial.

O grau de abertura dos países (Ln OPEN) foi inserido no modelo econométrico como variável de controle, pois acredita-se que a mesma pode determinar a margem extensiva do comércio internacional. 
Os resultados obtidos no presente trabalho parecem indicar que o grau de abertura ao comércio internacional do parceiro comercial tem alguma influência sobre a margem extensiva do comércio internacional, tendo em vista que o coeficiente associado a esta variável apresentou, na maior parte das estimações, nível de significância igual a $10 \%$. Analisando essa evidência em conformidade com o referencial teórico utilizado, acredita-se que deve existir alguma correlação negativa entre os custos fixos de entrada no mercado do parceiro comercial com o seu grau de abertura ao comércio.

Como esperado, a distância geográfica (Ln DIST $T_{i j}$ ) tem um impacto negativo e estatisticamente significativo sobre a margem extensiva do comércio internacional. Comumente, esta variável é vista como uma proxy dos custos de transporte (Nilsson, 1999), constituindo, dessa forma, uma barreira natural ao comércio. Os resultados aqui reportados indicam que a distância geográfica tende a majorar o custo de transporte, provocando uma redução na lucratividade das exportações. Em consequência disso, as firmas menos produtivas não conseguem penetrar os seus produtos nos mercados dos parceiros comerciais mais longínquos. Dennis e Shepherd (2007) e Pacheco e Pierola (2008) também verificaram que a distância geográfica tem um impacto negativo sobre a margem extensiva do comércio internacional.

As variáveis que representam o compartilhamento de fronteiras (FRONT) e a firmação de um acordo preferencial de comércio (APC) não apresentaram significância estatística. Particularmente, o fato dessa última variável não possuir significância estatística mostrou-se, de certa forma, surpreendente, haja vista que alguns trabalhos encontrados na literatura empírica, como, por exemplo, Piani e Kume (2000), destacam que a firmação de um acordo preferencial tem um impacto positivo sobre o comércio internacional. Mas, destaca-se que as evidências reportadas no presente trabalho coadunam com os achados de Pacheco e Pierola (2008), Álvarez et al. (2009) e Bergin e Lin (2009).

Pacheco e Pierola (2008) não encontram evidências de que a firmação do acordo preferencial de comércio, entre os países do Mediterrâneo e os países da União Europeia, teve um efeito positivo sobre a margem extensiva dos países envolvidos. Álvarez et al. (2009) verificaram que os acordos preferenciais de comércio entre 
os Estados Unidos e os seus parceiros comerciais não tem qualquer impacto sobre a margem extensiva dos países exportadores. Já em Bergin e Lin (2009), em um estudo com 148 países para o período entre 1973 a 2000, identificaram que os acordos preferenciais de comércio têm um efeito negativo sobre a margem extensiva do comércio. Dessa forma, com os resultados obtidos no presente trabalho, conjuntamente com os resultados encontrados em Pacheco e Pierola (2008), Álvarez et al. (2009) e Bergin e Lin (2009), pode-se inferir que os acordos preferenciais de comércio tendem a estimular, sobretudo, a margem intensiva do comércio internacional, onde os países envolvidos no acordo aumentam o volume monetário dos produtos que já são tradicionalmente comercializados, mas não conseguem introduzir novos produtos às suas pautas de exportação, isto é, incrementar as suas margens extensivas.

As evidências obtidas nas estimações indicam que o compartilhamento de idioma (IDIOMA) tem um efeito positivo sobre a margem extensiva do comércio internacional. De acordo com Andersson (2007), isso indica que o compartilhamento de idioma tende a reduzir os custos de comunicação. A redução dos custos de comunicação, por sua vez, tende a facilitar a penetração dos produtos nos mercados dos países envolvidos, aumentando as suas margens extensivas.

Quanto à análise do efeito da volatilidade da taxa de câmbio sobre a margem extensiva de comércio internacional, verifica-se que o coeficiente associado a essa variável é negativo e estatisticamente significativo (ao nível de 1\%), e que, ademais, esse resultado se mantém independentemente da medida de volatilidade da taxa de câmbio utilizada nas estimações. Como as medidas de volatilidade utilizadas nas estimações não estão logaritmizadas, seguindo Tenreyro (2007), o impacto dessas variáveis sobre a margem extensiva do comércio internacional deve ser mensurado da seguinte forma: ${ }^{16}$

$$
\frac{\partial \mathrm{E}\left(\mathrm{MEXT}_{\mathrm{ijt}} \mid \mathrm{x}_{\mathrm{ijt}}\right)}{\partial \mathrm{VOL}_{\mathrm{ijt}}} \times \frac{\mathrm{VOL}_{\mathrm{ijt}}}{\mathrm{MEXT}_{\mathrm{ijt}}}=\hat{\beta}_{1} \mathrm{VOL}_{\mathrm{ijt}}
$$

${ }^{16}$ É importante ressaltar que, como o modelo estimado é não linear, a magnitude da elasticidade dependerá do ponto escolhido. No presente trabalho utilizou-se o ponto médio da distribuição. 
Onde, $\hat{\beta}_{1}$ denota o coeficiente associado à medida da volatilidade da taxa de câmbio utilizada na estimação e $\mathrm{VOL}_{\mathrm{ijt}}$ será o valor médio da distribuição dessa variável.

Seguindo o modelo com Efeitos Fixos, os valores de $\hat{\beta}_{1}$ em relação às variáveis $S_{i j t}, W_{i j t}$ e $Z_{i j t}$ são, respectivamentes, iguais a: -0,151; -0,123 e -0,035 (ver Tabela 2); enquanto os valores médios das variáveis $S_{\mathrm{ijt}}, \mathrm{W}_{\mathrm{ijt}}$ e $Z_{\mathrm{ijt}}$ são, respectivamente, iguais a: 0,028; 0,044 e 0,154 (ver Apêndice I). Assim, a multiplicação dessas variáveis fornece elasticidades iguais a: -0,004; -0,005 e -0,005. Em outras palavras, os resultados aqui obtidos sugerem que o acréscimo de $1 \%$ na volatilidade da taxa de câmbio causa, em média, uma redução de 0,004\%; $0,005 \%$ e $0,005 \%$ na margem extensiva do comércio internacional. Ou seja, os resultados aqui obtidos evidenciam que a volatilidade da taxa de câmbio causa uma redução na margem extensiva do comércio internacional.

É importante aqui frisar que os resultados observados no presente estudo estão em linha com os de outros trabalhos encontrados na literatura, como, por exemplo, os desenvolvidos por Álvarez et al. (2009) e Lin (2012). Álvarez et al. (2008), mediante a utilização de um amplo banco de dados, com 92 países e para o período de 19722001, verificaram que a volatilidade da taxa real de câmbio afeta negativamente a diversificação da pauta de exportação. Conforme os resultados obtidos a partir do modelo benchmark, observou-se que a elevação de $1 \%$ na volatilidade da taxa real de câmbio causa, em média, uma redução de $0,0476 \%$ na diversificação da pauta de exportação dos países. Posteriormente, com a amostra dividida em países desenvolvidos (pertencentes à $\mathrm{OCDE}$ ) e em desenvolvimento, Álvarez et al. (2009) observaram que a volatilidade da taxa real de câmbio tem um efeito negativo, e estatisticamente significativo, apenas sobre os países em desenvolvimento, onde uma elevação de $1 \%$ na volatilidade da taxa real de câmbio causa, em média, uma redução de $0,0479 \%$ na diversificação da pauta de exportação destes países. Já Lin (2012), de posse de uma base de dados com fluxos bilaterais de comércio entre 148 países, para o período compreendido entre 1973 a 2004, verificou que a volatilidade da taxa nominal de câmbio tem um efeito negativo, e estatisticamente significativo, sobre a diversificação da pauta de exportação dos países. Conforme as estimações obtidas a partir de um modelo gravitacional de comércio, observou-se que a elevação de $1 \%$ na volatilidade da taxa nominal de 
câmbio causa, em média, uma redução de $0,0053 \%$ na diversificação da pauta de exportação dos países.

Mas porque a volatilidade da taxa de câmbio afeta negativamente a margem extensiva do comércio internacional? Conforme o modelo de firmas heterogêneas de Lin (2012), descrito na seção 2, a margem extensiva do comércio internacional é determinada, principalmente, pelo nível de produtividade das firmas e pelos custos de entrada no mercado internacional. Com a elevação da volatilidade da taxa de câmbio, o custo fixo de entrada no mercado internacional também é majorado, assim como, o nível de produtividade necessário para a firma adentrar neste mercado. Em consequência disto, as firmas menos produtivas, como não possuem o nível de produtividade suficiente para adentrar no mercado internacional, acabam se retirando do mesmo, reduzindo, com isto, o número de produtos comercializados pelos países; isto é, as suas margens extensivas.

Conforme Álvarez et al. (2009), a redução da margem extensiva pode ser bastante nociva, sobretudo, para os países em desenvolvimento, que tradicionalmente possuem pautas de exportações mais concentradas do que a dos países desenvolvidos. Isto porque as flutuações cambiais podem tornar os países mais dependentes de um conjunto mais reduzido de produtos de exportação, mitigando a capacidade dos países em expandir as suas cestas de exportação, e aumentando as suas vulnerabilidades aos choques externos.

\section{Considerações Finais}

Após o colapso do sistema de Bretton Woods, quando o câmbio passou de fixo para flutuante, no início dos anos setenta, uma extensa literatura procura identificar quais são os efeitos da volatilidade da taxa de câmbio sobre os fluxos comerciais. Mas destaca-se que a maior parte dessa literatura considera em suas análises apenas a margem intensiva do comércio (volume monetário), negligenciando a outra parte, que corresponde à margem extensiva (número de produto). A separação do comércio internacional nesses dois fluxos emergiu na literatura com o surgimento dos modelos teóricos de firmas heterogêneas, cujo ponto de partida ocorreu com Melitz (2003). 
Diante desse contexto, o presente trabalho teve como objetivo central avaliar o efeito da volatilidade da taxa de câmbio sobre a margem extensiva do comércio internacional.

Conforme as três medidas de volatilidade da taxa de câmbio utilizadas nas estimações, os resultados obtidos sugerem que o aumento na volatilidade da taxa de câmbio causa uma redução na margem extensiva do comércio internacional. Assim, os resultados obtidos se somam às evidências obtidas nos trabalhos de Álvarez et al. (2009) e Bergin e Lin (2009), que também identificaram um efeito negativo da volatilidade da taxa de câmbio sobre a margem extensiva do comércio.

Conforme o modelo de firmas heterogêneas de Lin (2012), a margem extensiva do comércio internacional é determinada pelo nível de produtividade das firmas e pelos custos de entrada no mercado internacional. Com a elevação da volatilidade da taxa de câmbio, o custo fixo de entrada no mercado internacional também é majorado, bem como, o nível de produtividade necessário para a firma adentrar neste mercado. Como consequência, as firmas menos produtivas, não possuindo o nível de produtividade necessário para adentrar no mercado internacional, acabam se retirando do mesmo; o que reduz o número de produtos comercializados pelos países.

Apesar de todo o esforço metodológico empregado no presente trabalho, os resultados aqui não esgotam todas as discussões acerca dos efeitos da volatilidade da taxa de câmbio sobre a margem extensiva do comércio internacional. Sendo assim, extensões deste artigo podem utilizar outras medidas de volatilidade da taxa de câmbio, outras formas de mensurar a margem extensiva do comércio internacional, bem como utilizar outras especificações de modelo empírico. 


\section{Referências}

AGOSIN, M. Export diversification and growth in emerging economies. CEPAL Review 97, abril, 2009.

AL-MARHUBI, F. A. Export diversification and growth: an empirical investigation. Applied Economics Letters, vol. 7, p. 559-562, 2000.

ÁLVAREZ, R.; DOYLE, M.; LÓPEZ, R. A. Exchange rate volatility and export margins. Central Bank of Chile, working paper $\mathrm{n}^{\circ} 539,2009$.

ANDERSON, J. A theoretical foundation for the gravity equation. American Economic Review, vol. 69, p. 106-16, 1979.

ANDERSON, J., VAN WINCOOP, E. Gravity with gravitas: a solution to the border puzzle. American Economic Review, v. 93, p. 170-192, 2003.

ANDERSSON, M. Entry costs and adjustments on the extensive margin: an analysis of how familiarity breeds exports. Electronic Working Paper Series, working paper nº 81, 2007.

ARAÚJO, E. Volatilidade cambial e crescimento econômico: teorias e evidências para economias em desenvolvimento e emergentes (1980 e 2007). Economia, Brasília (DF), v.12, n.2, p.187-213, mai/ago 2011.

ARISTOTELOUS, K. Exchange-rate volatility, exchange-rate regime, and trade volume: evidence from the UK-US export function (1989-1999). Economic Letters 72, 87-89, 2001.

AZEVEDO, A. F. Z.; PORTUGAL, M. S. e BARCELLOS NETO, P. C. F.; Impactos comerciais da Área de Livre Comércio da Américas: uma aplicação do modelo gravitacional. Revista de Economia Contemporânea, vol. 10, nº 2, p. 237-267, 2006.

BAHMANI-OSKOOEE, M.; HEGERTY, S.W. Exchange rate volatility and trade flows: a review article. Journal of Economic Studies, vol. 34, p. 211-255, 2007.

BALDWIN, R. The euro's trade effect. European Central Bank, working paper no 594, 2006.

BERGIN, P. R.; LIN, C. Exchange rate regimes and the extensive margin of trade. In: NBER International Seminar on macroeconomics. Org: FRANKEL, J.; PISSARIDES, C. University of Chicago Press, p. 201-227, April 2009.

BERGSTRAND, J. The generalized gravity equation, monopolistic competition and the factor-proportions theory of international trade. Review of Economics and Statistics, vol. 71, p. 143-53, 1989.

BITTENCOURT, M. V. L.; LARSON, D. W.; THOMPSON, S. R. Impactos da volatilidade da taxa de câmbio no comércio setorial do Mercosul. Estudos Econômicos, São Paulo, v. 37, n. 4, p. 791816, Outubro/Dezembro 2007.

BRENTON, P.; NEWFARMER, R. Watching more than the discovery channel: export cycles and diversification in development. Policy Research, working paper $\mathrm{n}^{\circ}$ 4302, 2007.

CAMERON, A. C.; TRIVEDI, P. K. Microeconometrics: methods and applications. Cambridge University Press, 2005.

CAMERON, A. C.; TRIVEDI, P. K. Microeconometrics using stata. Stata Press, 2009.

CHANEY, T. Distorted gravity: the intensive and extensive margins of international trade. American Economic Review, vol. 98, p. 1707-1721, 2008.

CHENG, I.; WALL, H.J. Controlling for heterogeneity in gravity models of trade and integration. Federal Reserve Bank of St. Louis Review, St. Louis, v. 87, n. 1, p. 49-63, 2005.

CHO, G.; SHELDON, I.M.; McCORRISTON, S. Exchange rate uncertainty and agricultural trade. American Journal of Agricultural Economics, vol. 84, p. 931-42, 2002.

CLARK, P., TAMIRISA, N., WEI, S.J. Exchange rate volatility and trade flows-some new evidence. International Monetary Fund (IMF), working paper, 2004. 
DEBAERE, P.; MOSTASHARI, P. Do tariffs matter for the extensive margin of international trade? An empirical analysis. Journal of International Economics, vol. 81, nº. 2, 163-169, 2010.

DELL'ARICCIA, G. Exchange rate fluctuations and trade flows: evidence from the European Union. International Monetary Fund (IMF), working paper nº 98/107, 1998.

DENNIS, A.; SHEPHERD, B. Barriers to entry, trade costs, and export diversification in developing countries. World Bank, working paper $\mathrm{n}^{\circ}$ 4.368, 2007.

FALVEY, R.; GREENAWAY, D.; YU, Z. Intra-industry trade between asymmetric countries with heterogeneous firms. The University of Nottingham, research paper 2004/05, 2004.

FEENSTRA, R.; MARKUSEN, J.; ROSE, A. Understanding the home Market effect and the gravity equation: the role of differentiating Goods. National Bureau of Economic Research (NBER), working paper n. 6804, November 1998.

FRANKEL, J.; WEI, S. Trade Blocs and Currency Blocs. NBER Working Paper nº 4335, 1993.

FRANKEL, J.; STEIN, E.; WEI, S. Trading blocs and the Americas: the natural, the unnatural, and the super-natural. Journal of Development Economics, v. 47, p. 61-95, 1995.

GAGNON, J. E. Exchange rate variability and the level of international trade. Journal of International Economics, vol. 34 (3-4), p. 269-287, 1993.

GAULIER, G.; ZIGNAGO, S. BACI: International database at the product-level. CEPII, working paper $n^{\circ} 2010-23,2010$.

HELPMAN, E.; MELITZ, M.; RUBINSTEIN, Y. Estimating trade flows: trading partners and trading volumes. The Quarterly Journal of Economics, vol. CXXIII, 2008.

HELPMAN, E. Imperfect competition and international trade: evidence from fourteen industrial countries. Journal of the Japanese and International Economies, vol. 1, p. 62-81, 1987.

HELPMAN, E., MELITZ, M., YEAPLE, S. Exports versus FDI with heterogenous firms. American Economic Review, vol. 94, p. 300-316, 2004.

HESSE, H. Export Diversification and economic growth. Commission on Growth and Development, working paper $\mathrm{n}^{\mathbf{0}} 21,2008$.

HONDROYIANNIS, G.; SWAMY, P. A. V. B; TAVLAS, G.; ULAN, M. Some further evidence on exchange-rate volatility and exports. Bank of Greece, working paper $\mathrm{n}^{\circ} 28,2005$.

HUMMELS, D.; KLENOW, P. The variety and quality of a nation's exports. American Economic Review, vol. 95, p. 704-723, 2005.

HWANG, H.; LEE, J. Exchange rate volatility and trade flows of the UK in 1990s. International Area Review, vol. 8 (1), p. 173-82, 2005.

KRUGMAN, P. Increasing returns, monopolistic competition and international trade. Journal of International Economics, vol. 9, p. 469-79, 1979.

KRUGMAN. P. Scale economies, product differentiation, and the pattern of trade. American Economic Review, vol. 70, p. 950-959, 1980.

KUMAR R.; DHAWAN, R. Exchange rate volatility and Pakistani's exports to the developed world 1974-85. World Development, vol. 19, p. 1225-40, 1991.

LIN, C. Exchange rate uncertainty and the extensive margin of exports. The B. E. Journal of Macroeconomics, vol. 12 (1), 2012.

MELITZ, M. The impact of trade on intra-industry reallocations and aggregate industry productivity. Econometrica, vol. 71, p. 1695-1726, 2003.

MELITZ, M.; OTTAVIANO, G. Market size, trade and productivity. National Bureau of Economic Research (NBER), working paper n. 11393, June 2005.

MCKENZIE, M. D.; BROOKS, R. The impact of exchange rate volatility on German - US trade flows. Journal of International Financial Markets, Institutions and Money, vol. 7, p. 73-87, 1997. 
MCKENZIE, M. D. The impact of exchange rate volatility on Australian trade flows. Journal of International Financial Markets, Institutions and Money, vol. 8, p.21-38, 1998.

MUKHERJEE, D.; POZO, S. Exchange-rate volatility and trade: a semiparametric approach. Applied Economics, v. 43 (13), p. 1617-1627, 2011.

NILSSON, L. Two-way trade between unequal partners: the EU and the developing countries. Weltwirtschaftliches Archiv, vol. 135(1), p. 102-127, 1999.

OZTURK, I. Exchange rate volatility and trade: a literature survey. International Journal of Applied Econometrics and Quantitative Studies, vol.3-1, 2006.

PACHECO, A.; D, PIEROLA. Patterns of export diversification in developed countries: intensive and extensive margins. World Bank Policy Research, working paper $\mathrm{n}^{\circ}$ 4473, 2008.

PEREE, E., STEINHERR, A. Exchange rate uncertainty and foreign trade. European Economic Review, vol. 33, p. 1241-1264, 1989.

PIANI, G.; KUME, H. Fluxos bilaterais de comércio e blocos regionais: uma aplicação do modelo gravitacional. Pesquisa e Planejamento Econômico, Rio de Janeiro, v. 30, n. 1, p. 1-22, abr. 2000.

ROSE, A. One money one market: estimating the effect of common currencies on trade. Economic Policy, v. 15, p. 7-46, 2000.

SANTOS SILVA, J.M.C.; TENREYRO, S. The log of gravity. The Review of Economics and Statistics, Cambridge, v. 88, n. 4, 2006.

SHELDON, I.; MISHRA, S. K.; PICK, D.; THOMPSON, S. R. Exchange rate uncertainty and US bilateral fresh fruit and fresh vegetable trade: an application of the gravity model. Applied Economics, vol. 45, p. 2067-2082, 2013.

SHEPHERD, B. Geographical diversification of developing country exports. Munich Personal Repec Archive (MPRA), paper n ${ }^{\circ}$ 11267, 2008.

TENREYRO, S. On the impact of nominal exchange rate volatility. Journal of Development Economics, v. 82, p. 485-508, 2007.

WESTERLUND, J.; WILHELMSSON, F. Estimating the gravity model without gravity using panel data. Applied Economics, vol. 43, p. 641-649, 2011.

WILLIAMSON, J. Economia aberta e a economia mundial: um texto de economia internacional. Ed. Campus, $13^{\mathrm{a}}$ Tiragem, 1988.

WOOLDRIDGE, J. M. Econometric analysis of cross section and panel data. Cambridge, MA: MIT Press, 2002.

YAPLE, S. R. A simple model of firm heterogeneity, international trade, and wages. Journal of International Economics, vol. 65, p. 1-20, 2005. 
APÊNDICE I - Estatística descritiva das variáveis.

\begin{tabular}{|c|c|c|c|c|c|c|}
\hline Variável & & Média & Desv.-Pad. & Mínimo & Máximo & Observações \\
\hline \multirow{3}{*}{ MEXT } & overall & 929,8507 & 1143,7760 & 0,0000 & 4938,0000 & 42.930 \\
\hline & between & & 1134,7020 & 0,0667 & 4781,6670 & 2.862 \\
\hline & within & & 145,2430 & $-2429,4160$ & 2130,3170 & 15 \\
\hline \multirow{3}{*}{$S_{i j t}$} & overall & 0,0282 & 0,0281 & 0,0009 & 0,4041 & 42.930 \\
\hline & between & & 0,0117 & 0,0030 & 0,0793 & 2.862 \\
\hline & within & & 0,0256 & $-0,0315$ & 0,3790 & 15 \\
\hline \multirow{3}{*}{$W_{i j t}$} & overall & 0,0449 & 0,0386 & 0,0010 & 0,5668 & 42.930 \\
\hline & between & & 0,0174 & 0,0032 & 0,1085 & 2.862 \\
\hline & within & & 0,0344 & $-0,0429$ & 0,5066 & 15 \\
\hline \multirow{3}{*}{$Z_{i t}$} & overall & 0,1541 & 0,1476 & 0,0034 & 2,8636 & 42.930 \\
\hline & between & & 0,0641 & 0,0103 & 0,4397 & 2.862 \\
\hline & within & & 0,1329 & $-0,2189$ & 2,5779 & 15 \\
\hline \multirow{3}{*}{$\operatorname{LnPIB}_{i t}$} & overall & 5,4351 & 1,6122 & 2,0541 & 9,5674 & 42.930 \\
\hline & between & & 1,5925 & 2,4655 & 9,2767 & 2.862 \\
\hline & within & & 0,2528 & 4,6771 & 6,2748 & 15 \\
\hline \multirow{3}{*}{$\operatorname{Ln} \mathrm{PIB}_{j t}$} & overall & 5,4351 & 1,6122 & 2,0541 & 9,5674 & 42.930 \\
\hline & between & & 1,5925 & 2,4655 & 9,2767 & 2.862 \\
\hline & within & & 0,2528 & 4.6771 & 6,2748 & 15 \\
\hline \multirow{3}{*}{$\operatorname{Ln~DIST}_{i j}$} & overall & 8,7375 & 0,8799 & 5,0808 & 9,8858 & 42.930 \\
\hline & between & & 0,8800 & 5,0808 & 9,8858 & 2.862 \\
\hline & within & & 0,0000 & 8,7375 & 8,7375 & 15 \\
\hline \multirow{3}{*}{$\mathrm{APC}_{i j t}$} & overall & 0,1773 & 0,3819 & 0,0000 & 1,0000 & 42.930 \\
\hline & between & & 0,3641 & 0,0000 & 1,0000 & 2.862 \\
\hline & within & & 0,1153 & $-0,7561$ & 0,9106 & 15 \\
\hline \multirow{3}{*}{$\mathrm{FRONT}_{\text {it }}$} & overall & 0,0377 & 0,1906 & 0,0000 & 1,0000 & 42.930 \\
\hline & between & & 0,1906 & 0,0000 & 1,0000 & 2.862 \\
\hline & within & & 0,0000 & 0,0377 & 0,0377 & 15 \\
\hline \multirow{3}{*}{ IDIOMA $_{i j}$} & overall & 0,1565 & 0,3634 & 0,0000 & 1,0000 & 42.930 \\
\hline & between & & 0,3634 & 0,0000 & 1,0000 & 2.862 \\
\hline & within & & 0,0000 & 0,1565 & 0,1565 & 15 \\
\hline
\end{tabular}

Fonte: Base de dados. 